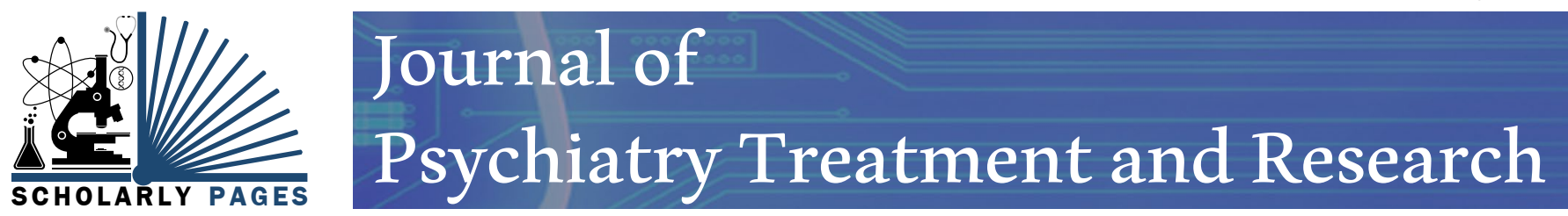

Clinical Study

Open Access

\title{
Patient Attitudes toward the Use of the Electronic Medical Record in an Acute Psychiatric Unit
}

\author{
Thomas Wise $^{1 *}$, Kevin Sethi ${ }^{2}$ Roy Kim ${ }^{3}$ and Maria Hadjikyriakou ${ }^{4}$
}

${ }^{1}$ Professor of Psychiatry, Inova Campus, Inova Fairfax Hospital, Virginia Commonwealth University School of Medicine, Virginia, USA

${ }^{2}$ Resident in Psychiatry, University of Michigan, Michigan, USA

${ }^{3}$ Resident in Anesthesiology, Johns Hopkins University, Maryland, USA

${ }^{4}$ Inova Campus, Inova Fairfax Hospital, Virginia Commonwealth University School of Medicine, Virginia, USA

\begin{abstract}
Background: The increasing use of the electronic medical record (EMR) has been promoted to enhance communication between health care professionals and medical settings. A common criticism, however, has been the EMR's effect upon the doctor-patient relationship and patient satisfaction. Current literature on such effects of the EMR has primarily involved the outpatient setting. This study instead surveys patient attitudes toward the use of the EMR in an acute, inpatient psychiatric setting.

Methods: A 13-item survey was administered to voluntary patients admitted to an acute psychiatric unit within a general hospital. Survey items were used to assess satisfaction with one's physician and medical care, sense of computer interference with the doctor-patient relationship, confidentiality concerns, and overall comfort with computer use on the unit.

Results: Data analysis revealed that $87.2 \%$ of the surveyed patients were comfortable with the use of computers on the unit, with only $11.5 \%$ of patients strongly agreeing that the computer acted as a barrier between them and their psychiatrists. However, comfort with computer use was not significantly associated with the other survey subfactors. Significant correlations among subfactors were found between physician satisfaction and sense of protected confidentiality $(\mathrm{r}=0.753, \mathrm{p}=0.01)$; between physician dissatisfaction and sense of protected confidentiality $(r=-0.353, p=0.05)$, confidentiality concerns $(r=0.438, p=0.01)$, and sense of computer interference $(r=0.450, p=0.01)$; and between sense of computer interference and confidentiality concerns $(r$ $=0.413, p=0.01)$. Patients who possessed an email address were less likely to feel that the computer interfered in their medical care $(\mathrm{r}=-0.328, \mathrm{p}=0.01)$.

Conclusions: Consistent with the current literature on EMR use in the outpatient setting, the majority of this study's patients in the acute, inpatient psychiatric setting were generally comfortable with EMR use during their interactions with nurses and physicians. However, this study found that patient attitudes toward the use of a computer and the EMR in an acute psychiatric setting are influenced by patients' concerns regarding medical record confidentiality and their view regarding the extent to which computer use in inputting data acts as a barrier during their time with medical care providers.
\end{abstract}

Keywords

Electronic Medical Records, Psychiatry, Physician-EMR Interaction, Physician-Patient Interaction, Medical Record Confidentiality, Computer Security, Patient Satisfaction, Quality of Care

List of Abbreviations

EMR: Electronic Medical Record

\section{Introduction}

The electronic medical record is increasingly utilized in hospital and ambulatory settings. The rationale for such digital "record keeping" has been to enhance communication between health providers in different locations [1]; to reduce medical errors [2]; and to aid in the devel-

Copyright: (c) 2017 Wise T, et al. This is an open-access article distributed under the terms of the Creative Commons Attribution License, which permits unrestricted use, distribution, and reproduction in any medium, provided the original author and source are credited. 
opment of larger health information databases as a way of improving evidence-based practice [3].

Nevertheless, criticism of electronic data systems by healthcare providers is emerging as physicians and nurses report that the electronic record increases time spent on charting vital clinical information [4]; fosters inaccuracies due to the high prevalence of copying and pasting of data from prior, possibly, inaccurate records [5,6]; and creates a literal barrier (the computer) between the patient and caregiver. Montague, et al. found that primary care physicians focus on the computer screen $30.7 \%$ of the time during medical visits, spending only $46.5 \%$ of the time looking directly at the patient [7]. Even when the computer screen was situated between the doctor and patient to allow for active information sharing, Asan, et al. found that the physician gazed at the patient only $46.1 \%$ of the time, spending $34.8 \%$ of the time gazing at technology [8]. Such a focus upon data entry could limit the clinician's ability to view the patient's emotional reactions throughout the medical interview and may affect the patients' view of their psychiatrist. Additionally, reliance on the computer for discrete information from the electronic record may limit the use of open-ended questions needed to obtain better narratives from patients.

Surveys of patient perception of computerized medical records suggest that most primary care patients as well as those in outpatient psychiatric settings are comfortable with electronic platforms $[2,9,10]$. Cavuoto, et al. through a prospective cross-sectional survey administered to young patients and parents/guardians of patients younger than 18-years-old within a pediatric ophthalmology clinic, found that patient satisfaction remained high throughout the installment of an EMR within the practice. Additionally, perceived time spent with physicians was either correct or overestimated during the postEMR installation phase [11]. Garrison, et al. similarly found that a majority of surveyed family medicine clinic patients thought that the computer had a positive impact on quality of medical care provided [12].

However, similar research has not been done within inpatient psychiatric settings. Thus, this study investigates patient attitudes toward the use of computers, which are used to input data in electronic medical records by psychiatrists and nurses, in an acute psychiatric unit within a general hospital.

\section{Materials and Methods}

The study, which was approved by the hospital's Investigational Review Board, was conducted in a 34-bed acute psychiatric unit within an 850-bed teaching hospital over three consecutive months in 2015. Two-thirds of the patients on this unit are admitted via the emergency room and stay for an average length of 5.6 days. This psychiatric unit is staffed by four full-time psychiatrists, residents, medical students, advanced practice nurses, and psychiatric nursing personnel.

Subjects for the study were voluntary patients who were on the psychiatric unit for at least 48 hours. Subjects could decline to participate at any time. Initial histories by the attending psychiatrist were often completed with concurrent data input into a computer. During their hospital stay, patients experienced multidisciplinary rounds, during which an attending physician used a computer terminal for clinical data input in the presence of the patient. These patients also experienced nursing rounds at least twice a day, during which time the nursing staff also utilized a computer to record vital signs and other clinical data in the presence of the patient. Thus, all subjects experienced computers as part of their hospital experience.

Demographic and diagnostic data were recorded for each patient. All DSM-IV diagnoses were obtained from the attending notes and subsequent evaluations. Data regarding patients' possession and use of an email address was additionally collected to further aid in result analysis.

Each patient was administered a 13-question survey (Figure 1), which was adapted from the 18-question short form of the RAND patient satisfaction questionnaire [13]. Patients responded to each item using a 5-point Likert scale. The complete 13-item survey had a Cronbach's alpha value of 0.654 .

A factor analysis was performed with varimax rotation to develop subfactors within the survey instrument for further data investigation. Cronbach's alpha values for categories of specific surveys items are as follows: the items related to satisfaction with one's medical care and their physician $(\mathrm{q}=1,2,4,8)$ had an alpha value of 0.723 ; items related to dissatisfaction with their physician $(\mathrm{q}=$ $3,5,6,7)$ had an alpha value of 0.903 ; and items measuring computer interference with the patient-health care provider relationship $(\mathrm{q}=11,12)$ had an alpha value of 0.918 . The items pertaining to confidentiality, including question 9 ("My psychiatric record was kept confidential") and question 10 ("I worry about who sees my psychiatric record"), were not significantly associated with

*Corresponding authors: Thomas N Wise, M.D., Professor of Psychiatry, Inova Campus, Inova Fairfax Hospital, Virginia Commonwealth University School of Medicine, 3300 Gallows Road, Falls Church, Virginia 22042, USA, E-mail: thomas.wise@inova.org

Received: February 01, 2017; Accepted: April 08, 2017; Published online: April 10, 2017

Citation: Wise T, Sethi K, Kim R (2017) Patient Attitudes toward the Use of the Electronic Medical Record in an Acute Psychiatric Unit. J Psychiatry Treat Res 1(1):1-7 


\begin{tabular}{|c|c|c|c|c|c|}
\hline \multicolumn{6}{|c|}{$\begin{array}{l}\text { How strongly do you AGREE or DISAGREE with each of the following statements? } \\
\text { (Circle one number on each line) }\end{array}$} \\
\hline & $\begin{array}{l}\text { Strongly } \\
\text { agree }\end{array}$ & Agree & Uncertain & Disagree & $\begin{array}{l}\text { Strongly } \\
\text { Disagree }\end{array}$ \\
\hline $\begin{array}{l}\text { 1. Doctors are good about } \\
\text { explaining the reason for my } \\
\text { care, such as drugs they use } \\
\text { and tests that I undergo }\end{array}$ & 1 & 2 & 3 & 4 & 5 \\
\hline $\begin{array}{l}\text { 2. The medical care I have } \\
\text { been receiving is very good }\end{array}$ & 1 & 2 & 3 & 4 & 5 \\
\hline $\begin{array}{l}\text { 3. Doctors act too business } \\
\text { like and impersonal toward } \\
\text { me }\end{array}$ & 1 & 2 & 3 & 4 & 5 \\
\hline $\begin{array}{l}\text { 4. My doctors treat me in a } \\
\text { very friendly and courteous } \\
\text { manner }\end{array}$ & 1 & 2 & 3 & 4 & 5 \\
\hline $\begin{array}{l}\text { 5. Those who provide my } \\
\text { medical care sometimes hurry } \\
\text { too much when they treat me }\end{array}$ & 1 & 2 & 3 & 4 & 5 \\
\hline $\begin{array}{l}\text { 6. Doctors sometimes ignore } \\
\text { what I tell them }\end{array}$ & 1 & 2 & 3 & 4 & 5 \\
\hline $\begin{array}{l}\text { 7. I have some doubts about } \\
\text { the ability of the doctors who } \\
\text { treat me }\end{array}$ & 1 & 2 & 3 & 4 & 5 \\
\hline $\begin{array}{l}\text { 8. Doctors usually spend } \\
\text { plenty of time with me }\end{array}$ & 1 & 2 & 3 & 4 & 5 \\
\hline $\begin{array}{l}\text { 9. My psychiatric record is } \\
\text { kept confidential }\end{array}$ & 1 & 2 & 3 & 4 & 5 \\
\hline $\begin{array}{l}\text { 10. I worry about who sees } \\
\text { my psychiatric record }\end{array}$ & 1 & 2 & 3 & 4 & 5 \\
\hline $\begin{array}{l}\text { 11. The computer gets in the } \\
\text { way of my psychiatrist and } \\
\text { myself as a patient }\end{array}$ & 1 & 2 & 3 & 4 & 5 \\
\hline $\begin{array}{l}12 . \text { The computer gets in the } \\
\text { way of my nurses and myself } \\
\text { as a patient }\end{array}$ & 1 & 2 & 3 & 4 & 5 \\
\hline $\begin{array}{l}\text { 13. I am comfortable with the } \\
\text { computer use in the unit }\end{array}$ & 1 & 2 & 3 & 4 & 5 \\
\hline
\end{tabular}

Figure 1: How strongly do you AGREE or DISAGREE with each of the following statements? (Circle one number on each line).

each other and thus were analyzed individually. The final question, a global summary question, "I am comfortable with the computer use on this unit", was treated as a separate variable.

\section{Results}

Over a 3-month period, one hundred subjects comprised the original study cohort, seventeen of which refused to participate. The patients that declined to participate did not differ in age or gender distribution, yet were more frequently diagnosed with schizophrenia $(70 \%$ in the declined participation group versus $21 \%$ in the final study cohort). There were no differences in age, gender, possession of an email address, or use of email services between the original and final study cohort.

Within the final study cohort, $53 \%$ of the subjects were male while $47 \%$ were female. The median age for the total group was 38.5 years (S.D. $=16.2$ ). Diagnostic data of the final cohort revealed $55 \%$ of subjects were diagnosed with unipolar depression, $21 \%$ diagnosed with schizophrenia or schizoaffective disorder, and the remaining $24 \%$ diagnosed with bipolar disorder. In terms of access and use of email services, $76 \%$ of patients stated that they possessed an email address, while only $70 \%$ reported they utilized their email regularly. There was no significant correla- 
tion between age and possession or use of email services.

The means of the direct responses to each survey question with their respective standard deviations are in Table 1. Correlations between the various subfactors of the survey are outlined in Table 2. Analysis revealed that physician and medical care satisfaction were positively correlated with sense of protected confidentiality, while physician dissatisfaction was negatively correlated with sense of protected confidentiality. In line with this latter finding, confidentiality concerns were positively correlated with

Table 1: Means and standard deviations for each survey question. Mean SD

1. Doctors are good about explaining the reason for my care, such as drugs they use and $1.90 \quad 1.150$ tests that I undergo.

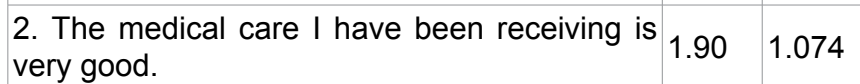

1.392

3. Doctors act too business like and impersonal $3.32 \quad 1.392$ toward me.

\begin{tabular}{|l|l}
1.79 & 1.024
\end{tabular}

\begin{tabular}{ll|l|l} 
4. My doctors treat me in a very friendly and & 1.79 & 1.024
\end{tabular} courteous manner.

3.321 .518

5. Those who provide my medical care sometimes hurry too much when they treat me.

\begin{tabular}{ll|l|l}
\hline 6. Doctors sometimes ignore what I tell them. & 3.26 & 1.587
\end{tabular}

\begin{tabular}{ll|l|l}
$\begin{array}{l}\text { 7. I have some doubts about the ability of the } \\
\text { doctors who treat me. }\end{array}$ & 3.58 & 1.473
\end{tabular}

8. Doctors usually spend plenty of time with me. $2.68 \quad 1.372$

\begin{tabular}{|l|l|l|}
\hline 9. My psychiatric record is kept confidential. & 2.01 & 1.327
\end{tabular}

10. I worry about who sees my psychiatric record. $2.60 \quad 1.632$

\begin{tabular}{|l|l|l|} 
11. The computer gets in the way of my psychiatrist & 3.77 & 1.404
\end{tabular} and myself as a patient.

$3.77 \quad 1.404$

\begin{tabular}{ll|l} 
12. The computer gets in the way of my nurses & 3.70 & 1.391
\end{tabular} and myself as a patient.

$1.85 \quad 1.239$

physician dissatisfaction. More importantly, physician dissatisfaction was positively correlated with the sense that the computer interfered with the individual's medical care. Interestingly, computer interference was negatively associated with sense of protected confidentiality and positively correlated with concerns about confidentiality, the latter correlation being the significant correlation of the two. One other salient finding was that those who had an email address were less likely to feel as though the computer interfered in their medical care $(\mathrm{r}=-0.328, \mathrm{p}=$ $0.01)$. Even when controlling for age, the above correlations remained significant. However, regression models failed to find any one variable or subset of variables that significantly correlated with the survey's global summary question pertaining to comfort with computer use.

Overall, based on question 13 of the survey, $87 \%$ of patients were comfortable with the use of computers on the psychiatric unit with no association with age. Supporting this, only $11.5 \%$ of patients strongly believed that the computer acted as a barrier between them and their psychiatrists, with only $9.9 \%$ strongly endorsing that the computer interfered with their care from their nurses (based on questions 11 and 12 of the survey).

\section{Discussion}

As hospitals and outpatient clinics are increasingly using electronic medical records, data is emerging about physician and patient attitudes toward such digital data repositories. The literature on reactions to the electronic record, primarily from physicians in outpatient care settings, focuses upon three areas of concern.

First, is the issue of confidentiality of the electronic formats. Based on an analysis of clinician survey responses, Salomon, et al. found that a significant majority of outpatient mental health clinicians in their study had concerns

Table 2: Pearson correlations between survey subfactors.

\begin{tabular}{|c|c|c|c|c|c|c|}
\hline & $\begin{array}{l}\text { Satisfaction } \\
\text { with physician } \\
\text { and medical } \\
\text { care }(q=1,2,4,8)\end{array}$ & $\begin{array}{l}\text { Physician } \\
\text { dissatisfaction } \\
(q=3,5,6,7)\end{array}$ & $\begin{array}{l}\text { Sense of } \\
\text { protected } \\
\text { confidentiality } \\
(q=9)\end{array}$ & $\begin{array}{l}\text { Confidentiality } \\
\text { concerns }(q=10)\end{array}$ & $\begin{array}{l}\text { Sense of } \\
\text { computer } \\
\text { interference } \\
(q=11,12)\end{array}$ & $\begin{array}{l}\text { Comfort } \\
\text { with } \\
\text { computer } \\
\text { use }(q=13)\end{array}$ \\
\hline $\begin{array}{l}\text { Satisfaction with } \\
\text { physician and medical } \\
\text { care }(q=1,2,4,8)\end{array}$ & 1 & $-0.625^{* *}$ & $0.753^{* *}$ & 0.009 & -0.001 & 0.064 \\
\hline $\begin{array}{l}\text { Physician dissatisfaction } \\
(q=3,5,6,7)\end{array}$ & $-0.625^{* *}$ & 1 & $-0.353^{*}$ & $0.438^{* *}$ & $0.450^{* *}$ & -0.044 \\
\hline $\begin{array}{l}\text { Satisfaction with medical } \\
\text { care ( } q=2 \text { only) }\end{array}$ & $0.875^{* *}$ & $-0.603^{* *}$ & $0.382^{* *}$ & -1.21 & -0.204 & -0.063 \\
\hline $\begin{array}{l}\text { Sense of computer } \\
\text { interference }(q=11,12)\end{array}$ & -0.001 & $-0.450^{* *}$ & -0.148 & $0.413^{* *}$ & 1 & -0.100 \\
\hline $\begin{array}{l}\text { Comfort with computer } \\
\text { use }(q=13)\end{array}$ & 0.064 & -0.044 & 0.008 & -0.092 & -0.100 & 1 \\
\hline
\end{tabular}


regarding privacy and data security of the EMR, leading to greater reluctance to include highly confidential information [14]. Greene catalogues the concerns and difficulties of privacy within the behavioral health EMR, citing the reluctance by many providers to share behavioral health information on the basis of their understanding of federal regulations regarding the "swapping of mental health records" [15]. For such reasons, Clemens, a psychoanalyst, is adamant that psychotherapy notes only be shared after obtaining explicit patient consent [16]. Fetter also emphasizes the importance of protecting behavioral health consumer rights in the preservation of mental health record confidentiality [17]. As Huff, et al. note, preserving EMR confidentiality is thought to help patients feel more comfortable in sharing their private health information with their healthcare providers [18].

The second area of concern focuses on the use of the computer during the patient encounter and its interference between the patient and physician in terms of both communication and the physician-patient relationship. Ober warns that the physician-patient relationship may be "under assault" with the introduction of the EMR in a general hospital, noting that the shortcuts inherent with the use of the EMR have made it more difficult for physicians to view the actual patients as subjective beings outside of their electronic medical record data [7]. Time consuming efforts involved in ordering test results, retrieving test results, and writing prescriptions have challenged the efficiency of patient care and detracted from time that could be spent face-to-face with patients. A 2005 study surveying various family physician practices found that $50 \%$ more time was spent on charting functions in the first 6 months of EMR implementation [4].

The third area of concern involves the reliability and accuracy of the electronic medical record data. Kaplan's article on "Electronic Health Records and Patient Privacy" notes that, while the EMR has allowed health care providers to access patient information from multiple locations, the information is often "legible gibberish" [19]. Interestingly, as evaluated in Salomon, et al.'s 2009 study, a survey of 120 university-based outpatient mental health clinicians revealed that most respondents believed that the EMR system allowed for a more complete and legible patient record, thought to "mildly" improve clinical care. However, most respondents did not necessarily believe that the EMR data was necessarily more factual [14].

It may be that clinicians are far more pessimistic than patients in their perception of the electronic medical record and computer use during a visit with a physician. Wang, et al., after all, have documented the differences in attitudes toward the inter-hospital electronic patient record between physicians and patients, noting physicians' more conservative approach to the EMR as compared to that of patients [20]. This current study found that most patients are comfortable with computer use on the inpatient psychiatric unit as it is used in patient care. This is in line with previous studies on EMR use in outpatient settings, both psychiatric and non-psychiatric. Stewart, et al. surveyed outpatient psychiatric patients and reported that patient survey responses to categories, including "overall", "technical", "interpersonal", "communication and education", "time", "confidentiality", "anxiety", and "computer use", were not significantly different before and after EMR implementation in clinical offices [21]. Irani, et al.'s systematic review on the effect of the EMR on patient satisfaction in primarily primary care settings did not find negative effects on patient satisfaction [9]. In fact, Kazley, et al. reported that EMR use improved patient satisfaction with hospitals [22].

When compared with paper record use, Solomon and Dechter found that there were no significant differences in patient satisfaction when physicians used a handwritten record versus a computer during the course of their study [23]. Through focus-group interviews of patients from a diabetic clinic, Rose, et al. found that most patients preferred electronic medical record use to paper record use in the physician office. Patients felt the EMR use allowed for more time with their providers, improved communication between providers, and reduced the time needed to look through past records as some were frustrated with the time providers spent flipping through the paper chart [24].

The data in this report suggests that patient satisfaction in an inpatient psychiatric unit is a complex subject involving patient concerns with medical record confidentiality. As Mwachofi, et al. reported, concerns regarding privacy of the EMR are not exclusive to clinicians [25]. Interestingly, Ancker, et al., in their survey of health care consumers within the United States over 2011 to 2013, found that concerns about privacy became less marked over time. Perhaps this signifies that with further exposure to technology; as it is used with the patient record, worries regarding the privacy of the EMR diminish. Over $70 \%$ of the patients in this study regularly used an email address and so this may have had an impact on patients' comfort with computer use on the unit, especially as use of an email was negatively correlated with the sense that the computer was a barrier. However, Solomon and Dechter did not find a correlation between patient satisfaction and previous patient exposure to computers [23].

Additional studies are needed to further investigate patient perceptions of the EMR as it is used in the hospital setting, specifically in the acute psychiatric setting, in order to optimize use of the EMR within the physician-patient relationship. With this and the further elucidation of EMR 
implementation, perhaps clinicians' perception of EMR may follow that of patients and evolve to an overall positive one. Bhe, et al., in surveying outpatient primary care providers, found that most physicians, once made aware of the accessibility of psychiatric notes as afforded by the EMR, felt that the availability of the psychiatric notes enhanced their care of patients with mental illness. These physicians noted that the EMR helped to improve their comfort with discussing psychiatric illnesses; to increase their awareness of medication side effects; and to optimize their communication with psychiatrists [1]. In the continuing analysis and study of EMR use, as outlined in a Pan-Canadian study of primary healthcare physicians, other areas of concern that must be addressed include further understanding the elements of EMR implementation, identifying the value of EMR implementation, agreeing on the uses and procedures of data-sharing, and developing effective means of data entry and extraction procedures [26].

Limitations of this study include using a cross sectional design, being limited to one inpatient psychiatric program, and utilizing a survey inventory that was not fully validated. In addition, the patients that declined participation in the study were most often diagnosed with schizophrenia. Thus, the question remains whether patients with this disorder view the EMR differently than those with other psychiatric disorders. Future studies would benefit from adding additional survey items to assess patients' trust in the computer system, confidence in the accuracy of the electronic data, and previous exposure to EMR use within the psychiatric setting.

\section{Conclusions}

This study aimed to contribute to the literature on patients' reactions to the use of the electronic medical record during patient encounters by being the first, to our knowledge, to investigate such reactions on the acute psychiatric unit within a general hospital. This study found that the majority of patients were generally comfortable with computer use in their daily hospital routine. Correlational analysis in this study suggests that there isn't any one variable that can predict comfort with computer use. Ultimately, patients' satisfaction and dissatisfaction with their healthcare providers and their overall medical care were associated with patients' sense of computer interference as it acts as a barrier to medical care and confidentiality.

\section{Acknowledgements}

\section{Ethics approval and consent to participate}

The study was approved by Inova Fairfax Hospital's Investigational Review Board. Research participants could decline to participate at any time.

\section{Consent for publication}

Not applicable.

\section{Availability of data and material}

The survey and full dataset may be obtained from the authors by contacting thomas.wise@inova.org.

\section{Competing interests}

The authors declare that they have no competing interests.

\section{Funding}

None.

\section{Author's contributions}

TW conceived and directed research, performed statistical analysis, drafted the manuscript, and approved final manuscript. KS and RK developed the survey tool and collected the research data. MH helped with the interpretation of statistical analysis and manuscript preparation.

\section{References}

1. Bhe E, Summers S, Pakyurek M, et al. (2015) Outpatient Psychiatric Documentation Use by Primary Care Physicians Following De-Sensitization in the Electronic Medical Record. Acad Psychiatry 39: 639-644.

2. Hsu J, Huang J, Fung V, et al. (2005) Health Information Technology and Physician-Patient Interactions: Impact of Computers on Communication during Outpatient Primary Care Visits. J Am Med Inform Assoc 12: 474-480.

3. Martin JC, Avant RF, Bowman MA, et al. (2004) The Future of Family Medicine: A Collaborative Project of the Family Medicine Community. Ann Fam Med 2: S3-S32.

4. Keshavjee K, Troyan S, Holbrook AM, et al. (2001) Measuring the Success of Electronic Medical Record Implementation Using Electronic and Survey Data. Proc AMIA Symp 2001: 309-313.

5. Thornton JD, Schold JD, Venkateshaia L, et al. (2013) Prevalence of Copied Information by Attendings and Residents in Critical Care Progress Notes. Crit Care Med 41: 382-388.

6. Fitzgerald FT (1999) On Being a Doctor: Curiosity. Ann Intern Med 130: 70-72.

7. Ober KP, Applegate WB (2015) The Electronic Health Record: Are we the tools of our tools? Pharos Alpha Omega Alpha Honor Med Soc 78: 8-14.

8. Asan $\mathrm{O}$, Young $\mathrm{H}$, Chewning $\mathrm{B}$, et al. (2005) How physician electronic health record screen sharing affects patient and doctor non-verbal communication in primary care. Patient Educ Couns 98: 310-316.

9. Irani JS, Middleton JL, Marfatia R, et al. (2009) The Use of Electronic Health Record in the Exam Room and Patient Satisfaction: A Systematic Review. J Am Board Fam Med 22: 553-562.

10. Liu J, Luo L, Zhang R, et al. (2012) Patient Satisfaction with Electronic Medical/Health Record: A Systematic Review. Scand J Caring Sci 27: 785-791. 
11. Cavuoto KM, Monsalve P, Chang TC (2016) The Impact of the Transition to an Electronic Medical Record on Patient Perceptions in a Pediatric Ophthalmology Practice. J Pediatr Opthalmol Strabismus 53: 173-178.

12. Garrison GM, Bernard ME, Rasmussen NH (2002) 21st- century health care: the effect of computer use by physicians on patient satisfaction at a family medicine clinic. Fam Med 34: $362-368$

13. Patient Satisfaction Questionnaire (PSQ-18). RAND Health.

14. Salomon R, Blackford JU, Rosenbloom ST, et al. (2009) Openness of patients' reporting with use of electronic records: psychiatric clinicians' views. J Am Med Inform Assoc 17: 54-60.

15. Greene J (2013) Behavioral Health Date in the Electronic Health Record: Privacy Concerns Slow Sharing. Ann Emerg Med 62: A19-A21.

16. Clemens NA (2012) Privacy, Consent, and the Electronic Mental Health Record: The Person vs. the System. J Psychiatr Pract 18: 46-50.

17. Fetter MS (2009) Personal Health Records: Protecting Behavioral Health Consumers' Rights. Issues Ment Health Nurs 30: 720-722.

18. Huff DJ, Huff, Powell (2014) EMR Confidentiality. J Med Assoc Ga 103: 20-22.

19. Kaplan A (2015) Electronic Health Records and Patient Privacy- An Oxymoron? Psychiatric Times.
20. Wang J, Ho H, Chen J, et al. (2015) Attitudes toward inter-hospital electronic patient record exchange: discrepancies among physicians, medical record staff, and patients. BMC Health Serv Res 15: 264.

21. Stewart RF, Kroth PJ, Schuyler M, et al. (2010) Do electronic health records affect the patient-psychiatrist relationship? A before \& after study of psychiatric outpatients. BMC Psychiatry 10: 3 .

22. Kazley AS, Diana ML, Ford EW, et al. (2012) Is electronic health record use associated with patient satisfaction in hospitals? Health Care Manage Rev 37: 23-30.

23. Solomon GL, Dechter M (1995) Are patients pleased with computer use in the examination room? J Fam Pract 41: 241-244.

24. Rose D, Richter LT, Kapustin J (2014) Patient experiences with electronic medical records: Lessons learned. J Am Assoc Nurse Pract 26: 674-680.

25. Mwachofi AK, Khaliq AA, Carrillo ER, et al. (2016) Technology versus humanism: how patients perceive the use of electronic health records in physicians' offices-a qualitative study. Health Commun 31: 257-264.

26. Terry A, Steward M, Fortin M, et al. (2014) Gaps in Primary Healthcare Electronic Medical Record Research and Knowledge: Findings of a Pan-Canadian Study. Healthc Policy 10: 46-59. 